\title{
Total parathyroidectomy with autotransplantation in patients with renal hyperparathyroidism: indications and surgical approach
}

\author{
Stavros Gourgiotis, Panagiotis Moustafellos, Charalabos Stratopoulos, Vasilis Vougas, \\ Spiros Drakopoulos, Evangelos Hadjiyannakis
}

First Surgical Department - Organ Transplant Unit, 'Evangelismos' General Hospital Athens, Greece

\begin{abstract}
OBJECTIVE: Renal hyperparathyroidism (RH) is one of the most serious complications in long-term hemodialysis patients. The purpose of this retrospective study was the evaluation of the surgical indications, parathyroid histology, and the results of total parathyroidectomy with autotransplantation $(\mathrm{PT}+\mathrm{At})$ in patients with $\mathrm{RH}$. DESIGN: The study included 36 patients with RH in whom PTx +At was carried out at the First Surgical Department of the Evangelismos Hospital over a 5-year period. Indications for PTx + At were high levels of parathyroid hormone (PTH > $800 \mathrm{ng} / \mathrm{L}$ ) associated with hypercalcemia and/or hyperphosphatemia, that were refractory to medical treatment, as well as clinical effects of $\mathrm{RH}$, including pruritus, bone and joints pain, muscle weakness, progression of soft tissue calcification, and spontaneous fractures. Ultrasonography, ${ }^{99 \mathrm{~m}} \mathrm{Tc}$ sestamibi scan and computed tomography were used to evaluate the thyroid and parathyroids. RESULTS: There was no mortality related to surgery. Preoperative symptoms, serum PTH, serum alkaline phosphatace, hyperphosphatemia, and hypercalcemia were improved or normalised in most patients. Recurrence was observed in one case; this autotransplanted patient required resection of transplanted tissue from his forearm. Hypoparathyroidism was not recorded. CONCLUSIONS: PTx+At is a safe option for the treatment of RH that is accompanied by low morbidity, mortality, and recurrence rate. It is important to identify all parathyroid glands at surgery and to choose adequate parathyroid tissue for autograft.
\end{abstract}

Key words: Autotransplantation, Parathyroidectomy, Renal hyperparathyroidism

\section{INTRODUCTION}

Secondary hyperparathyroidism (SHPT) is a common complication of end-stage renal failure and, despite improved medical management, $0.7-1.4 \%$ of dialysis dependent patients require parathyroidectomy annually. ${ }^{1}$ The association between parathyroid

\footnotetext{
Address correspondence and requests for reprints to:

Stavros Gourgiotis MD PhD, 21 Millersdale Road, Mossley Hill, L18 5HG, Liverpool, Tel. (home): +44(0) 151 724 3272, (work): +44(0) 151706 4169, Mobile: +44(0) 7757837724, Fax: +44(0) 151 706 5798, e-mail: drsgourgiotis@tiscali.co.uk \& s.gourgiotis@liv.ac.uk 
hyperplasia and chronic renal failure (CRF) has been known since the early $1930 \mathrm{~s}^{2} \mathrm{CRF}$ is characterized by reduced vitamin $\mathrm{D}$ levels, hyperphosphatemia, a tendency toward hypocalcemia, increased levels of PTH, and SHPT. ${ }^{3}$ SHPT is an adaptive response to CRF and the disruptions in the homeostatic control of serum phosphorus, calcium, and vitamin D that are associated with CRF. ${ }^{4}$ Excess circulating levels of $\mathrm{PTH}$, phosphate, and the calcium-phosphate product have been linked to uremic bone disease, vascular calcification, and death., ${ }^{5,6}$ Many authors have suggested that hyperplasia of parathyroid glands occurs during the early stages of renal disease before dialysis is required. ${ }^{7}$

Several medical therapeutic options for SHPT are currently available, aiming at reducing hyperphosphatemia, elevate serum calcium, reduce PTH, and improve skeletal turnover. ${ }^{7-9}$ For example, the administration of calcium supplements in the form of calcium carbonate or calcium acetate can be effective for managing PTH levels in some dialysis patients or in those with early stages of renal failure. ${ }^{10,11}$ Administration of vitamin D (calcitriol) also constitutes a promising form of prophylaxis and treatment of SHPT, while for those patients in whom dietary restriction is not sufficient to control serum phosphorus levels, phosphate-binding agents must be prescribed. ${ }^{12}$ However, several studies have demonstrated that most patients with excessively increased PTH levels values fail to respond to vitamin D treatment and surgical treatment is required., ${ }^{9,13}$ Parathyroidectomy can dramatically lower PTH and phosphate levels, but is typically reserved for patients with refractory secondary and tertiary hyperparathyroidism. ${ }^{14}$ In about $10-30 \%$ of patients in hemodialysis for more than 10 years, parathyroidectomy is required.

In the present study, we present our experience with 36 patients on dialysis who were subjected to PTx + At at our surgical department over a 5-year period. Specifically, we review the indications for surgery, describe the type of operation performed and present our results from the biochemical and imaging evaluation of these patients. The data were analyzed in terms of indications, type of surgical procedure, parathyroid histology, effect on clinical/laboratory indices, and postoperative complications.

\section{METHODS}

Between January 2000 and December 2004, we performed $\mathrm{PTx}+$ At in 36 patients for advanced $\mathrm{RH}$ out of a total of 81 patients with SHPT. The clinical results of the operations were obtained through a questionnaire that was answered by the patients during the follow-up examination. Throughout this period, all patients were still on dialysis.

Because indications for parathyroidectomy, as well as the response to parathyroidectomy, may differ between dialysis and transplant patients, patients undergoing PTx + At with a functioning transplant were excluded from the present study. Patients with repeat operations for recurrent or persistent hyperparathyroidism were also excluded from the study. The study group included 15 females and 21 males, with a mean age of $42 \pm 6.1$ years (mean $\pm S D)$. The mean duration of hemodialysis before the procedure was 123 months. CRF was caused by chronic glomerulonephritis in 22 cases, chronic pyelonephritis in 10 cases, and in 4 patients the cause was unknown.

In all the patients, medical therapy including calcium supplementation, dietary $\mathrm{PO}_{4}$ restriction, phosphate-binding agents, and pulsed oral/intravenous vitamin D sterol therapy failed to suppress the serum PTH level. Our surgical indications for PTx + At were severe hyperparathyroidism (PTH level >800ng/L in all cases) associated with hypercalcemia and/or hyperphosphatemia that were refractory to medical treatment. Surgery was also resorted to for those patients with clinical effects of RH including: pruritus in $24(66.6 \%)$ patients, bone and joints pain in $20(55.6 \%)$ patients, muscle weakness in $13(36.1 \%)$ patients, progression of soft tissue calcification in $10(27.8 \%)$ patients and spontaneous fractures in 3 $(8.3 \%)$ patients.

Serum calcium, phosphate, and total alkaline phosphatace were determined by standard methods. Serum PTH levels (normal: 15-65ng/L) were found to be $>800 \mathrm{ng} / \mathrm{L}$ in all cases. Serum calcium levels (normal: $2.12-2.62 \mathrm{mmol} / \mathrm{L}$ ) ranged from 2.15 to $3.57 \mathrm{mmol} / \mathrm{L} .25$ patients $(69.4 \%)$ were hypercalcemic (serum-calcium above $2.62 \mathrm{mmol} / \mathrm{L}$ ). Hypercalcemia was considered to be a consequence of treatment with vitamin $\mathrm{D}$ or vitamin $\mathrm{D}$-metabolites. The other patients were normo- or slightly hypocalcemic. Se- 
rum phosphorous (normal: $0.8-1.55 \mathrm{mmol} / \mathrm{L}$ ) was recorded between 1 and $3 \mathrm{mmol} / \mathrm{L}$. Normal values were found in 6 patients. Serum alkaline phosphatace (normal: below 200U/L) was normal in 4 patients and was elevated in the others.

Preoperative diagnosis was based primarily on thyroid ultrasonography (US) and ${ }^{99 \mathrm{~m}} \mathrm{Tc}$-sestamibi radionuclide scan, which were both performed in all patients preoperatively. Their sensitivity in determining the location and number of parathyroid glands was $63.9 \%$ and $77.8 \%$, respectively. Computed tomography (CT) was required in 22 patients $(61.1 \%)$ for additional information about the localization of parathyroids; the diagnostic sensitivity of CT was $91.7 \%$. X-rays of hands, feet, pelvis, and skull were performed to seek lesions of renal osteodystrophy; bone biopsy was not performed.

All patients were on chronic hemodialysis. They were dialysed the day before surgery, the next dialysis being performed on the first or second day post surgery. Prior to parathyroid surgery, a therapeutic trial with calcitriol was performed in all instances to lower PTH secretion.

$\mathrm{PTx}+$ At was the preferred procedure in this study. The thyroid and parathyroid glands were exposed through a conventional neck incision, with division of the strap muscles at the midline. The exploration of the neck was done according to the surgical anatomy of the parathyroids and with the assistance of the preoperative image diagnosis. Thymectomy from the neck incision was performed in 2 patients. For autotransplantation, 30 pieces sliced $1 \times 1 \times 3 \mathrm{~mm}$ of diffusely hyperplastic glands were implanted into 30 pockets in the forearm without the arteriorvenous (A-V) fistula for hemodialysis. These pieces were placed into the brachioradicalis muscle of the arm.

Serum calcium levels were determined at 8-hour intervals over the first 48 hours after the operation and then daily until stabilized. Supplemental calcium was given intravenously or by mouth. Vitamin D was started on the first postoperative day and was usually continued for 6 to 8 months.

Postoperative recurrence was diagnosed if serum PTH level increased to $>200 \mathrm{ng} / \mathrm{L}$ with normal serum calcium levels.

\section{RESULTS}

The median follow-up period was 2.7 years (range, 1.5-4.4 years). The number of excised parathyroid glands was: five in 4 patients, four in 29 patients, three in one patient and two in 2 patients. The weight of the glands removed ranged from 340 to $480 \mathrm{mg}$ (median $390 \mathrm{mg}$ ). Microscopic examination showed a diffuse hyperplasia in 8 and nodular chief cell hyperplasia in 28 cases.

There was no mortality related to surgery. Of the 36 patients, 34 are still alive one to six years after the procedure. Two patients died 13 and 24 months after surgery due to pneumonia and severe ischemic heart disease, respectively. The post operative complication rate was low; mild although asymptomatic postoperative hypocalcemia was noticed in 4 patients with high preoperative serum alkaline phosphatace levels, but this disturbance responded to intravenous calcium gluconate, high-dose calcitriol, and high dialysate calcium. Postoperative bleeding requiring surgical intervention or permanent hypocalcemia were not observed. Changes in voice tone attributable to injury of the external branch of superior laryngeal nerve, detected by postoperative clinical examination and laryngoscopy, were revealed in 2 patients; they experienced temporary hoarseness. No septic complication was noticed in the neck or the forearm wound.

The overall clinical and biochemical responses to PTx + At were good. Pruritus was relieved in 21 of 24 patients $(87.5 \%)$, bone pain disappeared or was significantly reduced in 19 of 20 patients (95\%), and myopathy disappeared in all patients within six months postoperatively (Figure 1). Soft tissue calcium deposits either disappeared or were markedly diminished within 7 months after parathyroidectomy. No pathological fractures occurred. By the third postoperative day, serum calcium dropped to within or below the normal range in all patients. Recurrent hypercalcemic hyperparathyroidism was not observed. During the follow-up years, mean serum calcium was $2.1 \pm 0.32 \mathrm{mmol} / \mathrm{L}$ (mean $\pm \mathrm{SD}$ ), serum phosphorus was $1.26 \pm 0.35 \mathrm{mmol} / \mathrm{L}($ mean $\pm \mathrm{SD})$, and serum alkaline phosphatase was $158 \pm 75 \mathrm{U} / \mathrm{L}$ (mean \pm SD). Serum PTH decreased in all patients. In 32 of them, it was found to be within the normal 


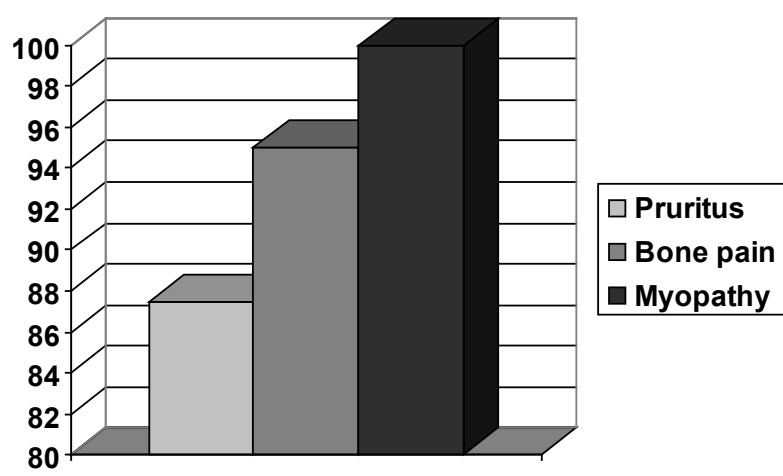

Figure 1. Relief of patients' symptoms (percentages) postoperatively.

range; in the others it was still elevated, the maximum being 2 times normal. Changes in serum biochemistry results are shown in Table 1.

Graft tissue took over function after 5.2 months on average (range, 1.7-6.1 months). Supplemental vitamin D and oral calcium could be stopped or reduced within that period of time. Recurrent graftdependent hyperparathyroidism was observed in

Table 1. Serum biochemistry results pre- and postoperatively

\begin{tabular}{|c|c|c|c|}
\hline & $\begin{array}{c}\text { Normal } \\
\text { values }\end{array}$ & $\begin{array}{c}\text { Preopera- } \\
\text { tively } \\
n\end{array}$ & $\begin{array}{c}\text { Postopera- } \\
\text { tively* } \\
\text { n }\end{array}$ \\
\hline $\begin{array}{l}\text { PTH } \\
>800 n g / L \\
\text { Normal }\end{array}$ & $15-65$ & $36(100)$ & $32(88.9)$ \\
\hline $\begin{array}{l}\text { Alkaline } \\
\text { phosphatace }\end{array}$ & $<200$ & & \\
\hline $\begin{array}{l}>\text { normal } \\
158 \pm 75 \mathrm{U} / \mathrm{L} \\
(\text { mean } \pm \mathrm{SD})\end{array}$ & & $32(88.9)$ & $36(100)$ \\
\hline $\begin{array}{l}\text { Calcium } \\
\text { > normal } \\
2.1 \pm 0.32 \mathrm{mmol} / \mathrm{L} \\
(\text { mean } \pm \mathrm{SD})\end{array}$ & $2.12-2.62$ & $25(69.4)$ & $36(100)$ \\
\hline $\begin{array}{l}\text { Phosphorus } \\
\qquad \text { normal } \\
1.26 \pm 0.35 \mathrm{mmol} / \mathrm{L} \\
(\text { mean } \pm \mathrm{SD})\end{array}$ & $0.8-1.55$ & $30(83.3)$ & $36(100)$ \\
\hline $\begin{array}{l}\text { *During the follow-up } \\
\text { years) } \\
\text { n: number of patients } \\
\text { Values in parentheses }\end{array}$ & $\begin{array}{l}\text { riod: me } \\
\text { percen }\end{array}$ & $2.7 \mathrm{ye}$ & nge, $1.5-4.4$ \\
\hline
\end{tabular}

one patient 12 months after removal of four glands and autografting. The serum PTH increased to 7 times normal and the serum calcium was between 2.3 and $2.5 \mathrm{mmol} / \mathrm{L}$. ${ }^{99 \mathrm{~m}} \mathrm{Tc}$ sintigraphy of the forearm showed high uptake in the grafted area. The transplanted parathyroid glands were excised under local anesthesia. Microscopic examination showed diffuse chief cell hyperplasia. After removal of parathyroid tissue from the forearm, serum PTH returned to near normal levels.

Radiologic examination of bones was carried out in 13 patients one or two years after surgery. Regression of osteodystrophy and improvement in soft tissue calcifications were observed in the majority $(84.6 \%)$ of patients.

\section{DISCUSSION}

Despite improvements in medical management, severe SHPT is a common complication of CRF. According to a report of the European Dialysis and Transplant Association, parathyroidectomy is required in $15 \%$ of patients after 10 years and in $38 \%$ after 20 years of dialysis. ${ }^{15}$

An increase in PTH is usually the principal indication for surgery in RH. All 36 patients included in our study had severe hyperparathyroidism (PTH $>800 \mathrm{ng} / \mathrm{L}$ ). Medical therapy had failed to suppress PTH or was complicated by hypercalcemia requiring discontinuation of calcium/vitamin D therapy. Similar results were reported by Salem ${ }^{16}$ in his survey of 612 chronic hemodialysis patients. He observed that $50 \%$ of patients showed serum PTH levels greater than three times normal, despite the usual medical therapy to prevent hyperparathyroidism. Hypercalcemia also strengthens the indication for surgery in RH. ${ }^{7,9,13}$ In our series, 25 patients had hypercalcemia; while 30 patients had hyperphosphatemia. The clinical effects of RH that was refractory to medical treatment were: pruritus, bone and joints pain, muscle weakness, progression of soft tissue calcification, and spontaneous fractures.

Many authors recommend that imaging of parathyroid glands should be done only prior to reoperation. They also propose that parathyroid imaging is not usually required before initial parathyroidec- 
tomy. ${ }^{17}$ Other authors consider that preoperative image diagnosis is very useful for detecting parathyroid glands, especially those which are ectopically located. ${ }^{18,19}$ The most important point is to visualize all the parathyroid glands, including supernumerary glands which are located mainly in fat surrounding the glands or within the thymus or around the carotid artery. ${ }^{20,21}$ Generally, supernumerary glands are found in $15-20 \%$ of patients. ${ }^{21,22}$ We routinely performed US and ${ }^{99 \mathrm{~m}} \mathrm{Tc}$ scintigram in all patients preoperatively to avoid the remaining supernumerary and/or ectopic parathyroid glands. ${ }^{99 \mathrm{~m}} \mathrm{Tc}$-sestamibi showed the highest sensitivity for localizing diseased glands. Sestamibi scan was successful in identifying all hyperplastic tissue in 28 patients with only 8 cases demonstrating false-negative results. US was our primary localization procedure as it is non-invasive and non-cost-intensive and it was successful in localazing the parathyroids in 23 patients. We also found that US was helpful for the detection of intrathyroidal parathyroid gland. Finally, CT scan was required in 22 patients for additional information about the localization of parathyroids, while X-rays of hands, feet, pelvis, and skull were performed seeking lesions of renal osteodystrophy.

Patients that require parathyroidectomy frequently have complications in the form of ischemic heart disease, cardiac dysfunction and/or respiratory failure because of thoracic deformity, and cervical destructive spondyloarthropathy. In this study, all patients underwent preoperative evaluation of cardiac and respiratory functions performed by cardiologists and pneumonologists.

There are many variations in procedures applied to accomplish surgical parathyroidectomy. The surgical procedure of choice at our institution was $\mathrm{PTx}+\mathrm{At}$ with forearm autograft, considering that in cases of recurrence, repeat neck exploration is not required and we can determine the function of autografted parathyroid tissue by measuring PTH sampled from both forearms. ${ }^{23,24}$ Since renal transplantations are not very common, in Greece many patients require long-term hemodialysis after parathyroidectomy, and consequently the risk of recurrence of $\mathrm{RH}$ is not negligible.
At surgery, in order to prevent recurrence, there should be no remaining nodular hyperplastic and no nodular tissue should be used for transplantation; the frequency of graft-dependent recurrent hyperparathyroidism is significantly higher when nodular hyperplastic tissue is autotransplanted than when diffusely hyperplastic tissue is used. ${ }^{25,26}$ Our patients underwent bilateral exploration. The most crucial point was to identify all parathyroid glands, including supernumerary and ectopic glands. Some authors recommend mediastinal exploration and thymectomy to resect additional parathyroid glands and to avoid recurrence caused by cervical spilling. ${ }^{27}$ In our patients, however, we found 4 supernumerary glands; 2 of them were located in the thymus tongue, and thymectomy from the neck incision was performed. Two intrathyroidal supernumerary glands could be removed based on preoperative identification by US diagnosis.

Postoperative bleeding requiring surgical intervention was not observed, while mild asymptomatic hypocalcemia was observed in 4 cases, although they were receiving oral calcium supplements and calcitriol. None of our patients experienced respiratory problems due to edema or injury of the recurrent laryngeal nerve while temporary hoarseness was observed in 2 patients. Finally, no septic complication was noticed in the neck or the forearm wound.

In our series, bone pain was mostly periarticular in the shoulders, ankles, and heels, and sometimes generalized. A quick recovery was noted in about $95 \%$ of subjects within weeks after the operation. In patients with pruritus, the symptoms disappeared after surgery in most subjects $(87.5 \%)$. Myopathy disappeared in all patients while soft tissue calcium deposits either disappeared or were markedly diminished within months after the procedure.

In conclusion, total parathyroidectomy with autotransplantation in the forearm is very effective and adequate treatment for advanced renal hyperparathyroidism not suppressible by pharmacologic means. It is very important to identify all the parathyroid glands and to choose proper and adequate parathyroid tissue for autograft to prevent recurrence of hyperparathyroidism. 


\section{REFERENCES}

1. Cohen EP, Moulder JE, 2001 Parathyroidectomy in chronic renal failure: has medical care reduced the need for surgery? Nephron 89: 271-274.

2. Albright F, Baird PC, Cope O, Bloomberg E, 1934 Studies on the physiology of parathyroid glands. IV. Renal complications of hyperparathyroidism. Am J Med Sci 187: 49-65.

3. Moe SM, Drueke TB, 2003 Management of secondary hyperparathyroidism: the importance and the challenge of controlling parathyroid hormone levels without elevating calcium, phosphorus, and calcium-phosphorus product. Am J Nephrol 23: 369-379.

4. Slatopolsky E, Delmez JA, 1994 Pathogenesis of secondary hyperparathyroidism. Am J Kidney Dis 23: 229-236.

5. Ganesh SK, Stack AG, Levin NW, Hulbert-Shearon T, Port FK, 2001 Association of elevated serum PO (4), Ca x PO (4) product, and parathyroid hormone with cardiac mortality risk in chronic hemodialysis patients. J Am Soc Nephrol 12: 2131-2138.

6. Raggi P, Boulay A, Chasan-Taber S, et al, 2002 Cardiac calcification in adult hemodialysis patients. A link between end-stage renal disease and cardiovascular disease? J Am Coll Cardiol 39: 695-701.

7. Llach F, 1995 Secondary hyperparathyroidism in renal failure: the trade-off hypothesis revisited. Am J Kidney Dis 25: 663-679.

8. Akizawa T, Fukagawa M, Koshikawa S, Kurokawa K, 1993 Recent progress in management of secondary hyperparathyroidism of chronic renal failure. Curr Nephrol Hypertension 2: 558-565.

9. Fournier A, Moriniere PH, Oprisiou R, et al, 1995 1-alpha-Hydrovyvitamine D3 derivatives in the treatment of renal bone diseases: justification and optimal modalities of administration. Nephrol 71: 254-283.

10. Indridason OS, Quarles LD, 2000 Comparison of treatment for mild secondary hyperparathyroidism in hemodialysis patients. Durham Renal Osteodystrophy Study Group. Kidney Int 57: 282-292.

11. Teruel JL, Tenorio MT, Rodriguez JR, et al, 1999 Treatment of secondary hyperparathyroidism in hemodialysed patients with high dose calcium carbonate without vitamin D3 supplements. Am J Nephrol 19: 428-432.

12. Janssen MJ, van der Kuy A, ter Wee PM, van Boven WP, 1996 Aluminum hydroxide, calcium carbonate and calcium acetate in chronic intermittent hemodialysis patients. Clin Nephrol 45: 111-119.

13. Llach F, 1990 Parathyroidectomy in chronic renal failure: indications, surgical approach and use of calcitriol. Kidney
Int Suppl 29: 62-68.

14. de Francisco AL, Fresnedo GF, Rodrigo E, Pinera C, Amado JA, Arias M, 2002 Parathyroidectomy in dialysis patients. Kidney Int Suppl 80: 161-166.

15. Fassbinder W, Brunner FP, Brynger H, et al, 1991 Combined report on regular dialysis and transplantation in Europe. Nephrol Dial Transplant 6: 5-35.

16. Salem MM, 1997 Hyperparathyroidism in the hemodialysis population a survey of 612 patients. Am J Kidney Dis 29: 862-865.

17. Chang CW, Tsue TT, Hermreck AS, Baxter KG, Hoover LA, 2000 Efficacy of preoperative dual phase sestamibi scanning in hyperparathyroidism. Am J Otolaryngol 21: 355-359.

18. Takagi H, Tominaga Y, Uchida K, Yamada N, Morimoto T, Yasue M, 1983 Image diagnosis of parathyroid glands in chronic renal failure. Ann Surg 198: 74-79.

19. Takagi H, Tominaga Y, Uchida K, et al, 1986 Evaluation of image diagnosing methods of enlarged parathyroid glands in chronic renal failure. World J Surg 10: 605611.

20. Numano M, Tominaga Y, Uchida K, Orihara A, Tanaka Y, Takagi H, 1998 Surgical significance of supernumerary parathyroid glands in renal hyperparathyroidism. World J Surg 22: 1098-1103.

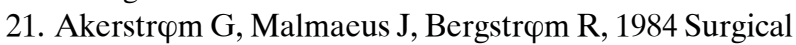
anatomy oh human parathyroid glands. Surgery 95: 1421.

22. Wang CA, 1976 The anatomic basis of parathyroid surgery. Ann Surg 183: 271-274.

23. Peeler BB, Mortin WH, Sandler MP, Goldstein RE, 1997 Sestamibi parathyroid scanning and preoperative studies for patients with recurrent/persistent hyperparathyroidism or significant comorbid conditions: development of an optimal localization strategy. Am Surg 63: 37-46.

24. Skinner KA, Zuckerbraun L, 1996 Recurrent secondary hyperparathyroidism. Arch Surg 131: 724-727.

25. Tanaka Y, Seo H, Tominaga Y, Funahashi H, Matsui N, Takagi H, 1993 Factors related to recurrent hyperfunction of autografts after total parathyroidectomy in patients with severe secondary hyperparathyroidism. Surg Today 23: 220-227.

26. Tominaga Y, Uchida K, Haba T, et al, 2001 More than 1,000 cases of total parathyroidectomy with forearm autograft for renal hyperparathyroidism. Am J Kidney Dis 38: 4 Suppl 1: 168-171.

27. Rothmund M, Wagner M, Pluntke K, 1999 Reoperationen bei persistierenden oder rezidivierenden Hyperparathyroidismus. Chirurg 70: 1113-1122. 